\title{
CONHECIMENTO DE PLANTAS MEDICINAIS E RELAÇÃO COM O AMBIENTE POR ALUNOS DE DUAS ESCOLAS DE ENSINO FUNDAMENTAL DO MUNICÍPIO DE VIÇOSA DO CEARÁ, CEARÁ
}

\author{
Idelson Pereira de Oliveira ${ }^{1}$ \\ Melise Pessôa Araújo ${ }^{2}$ \\ Victor de Jesus Silva Meireles ${ }^{3}$ \\ Jesus Rodrigues Lemos ${ }^{4}$
}

\section{Resumo:}

O uso de plantas entre as populações nordestinas indica um grande conhecimento dos recursos do ambiente e um sistema próprio de utilização desses recursos. Nesse contexto, o presente trabalho teve como objetivo verificar se há diferença entre o conhecimento acerca do uso medicinal de plantas apresentado por alunos de duas escolas de Ensino Fundamental da zona rural e urbana no município de Viçosa do Ceará. O numero de citações de plantas medicinais diferiu significativamente nos grupos da escola urbana e rural, sendo que este último demonstrou um maior conhecimento. Não foi verificada diferença acentuada quando comparada à diversidade de espécies citadas. Das plantas citadas pelos alunos da escola de zona urbana, metade foi similar àquelas também referidas pelos alunos da escola rural. Verificou-se que o conhecimento que as novas gerações possuem a respeito de plantas medicinais é relativamente representativo, sendo a família o principal transmissor do mesmo.

Palavras-chave: Etnobotânica. Conhecimento tradicional. Meio Ambiente.

\section{KNOWLEDGE ABOUT MEDICINAL PLANTS AND RELATIONSHIP WITH ENVIRONMENT FROM STUDENTS OF TWO BASIC EDUCATION SCHOOLS IN MUNICIPALITY VIÇOSA DO CEARÁ, CEARÁ STATE}

\begin{abstract}
:
The use of medicinal plants among the northeast populations of the Brazil indicates a great knowledge of environmental resources and a specific system of the use of these resources. In this context, the objective of this work is to verify if there is difference between the students' knowledge about the use of medicinal plants in two different schools, one in the rural and the other in the urban area, in the municipality Viçosa do Ceará. The number of mentioned medicinal plants differed significantly in both groups, and the students from the rural school demonstrated larger knowledge. Regarding the diversity of mentioned species, a broad difference was not verified. Considering the plants mentioned by the students from the urban school half was similar to those mentioned by the students from the rural school. It was verified that the new generations' knowledge about medicinal plants is relatively considerable and that the family is the main responsible for this transmission.
\end{abstract}

Keywords: Ethnobotany. Traditional knowledge. Environment.

\footnotetext{
${ }^{1}$ Graduado em Ciências Biológicas pela Universidade Federal do Piauí-UFPI. idelsonolv@hotmail.com

${ }^{2}$ Mestre em Desenvolvimento e Meio Ambiente-UFPI. melisepessoa@yahoo.com.br

${ }^{3}$ Mestre em Desenvolvimento e Meio Ambiente-UFPI. biologomeireles@yahoo.com.br

${ }^{4}$ Professor Associado I da Universidade Federal do Piauí/Campus Ministro Reis Velloso (Parnaíba). jelemos@ib.usp.br
} 


\section{EL CONOCIMIENTO DE LAS PLANTAS MEDICINALES Y SU RELACIÓN CON EL MEDIO AMBIENTE PARA LOS ESTUDIANTES DE DOS ESCUELAS PRIMARIAS EN EL MUNICIPIO DE VIÇOSA DO CEARÁ, CEARÁ}

\section{Resumen:}

El uso de plantas por la población del noreste del Brasil indica un gran conocimiento de los recursos ambientales y un sistema adecuado de la utilización de estos recursos. En este contexto, el presente estudio tuvo como objetivo verificar si hay una diferencia entre el conocimiento del uso medicinal de las plantas, presentado por estudiantes de dos escuelas primarias de las zonas rurales y urbanas de Viçosa do Ceará. El número de citaciones de plantas medicinales difirió significativamente en los grupos de la escuela urbana y rural, y este último mostró un conocimiento mayor. No hubo diferencia notable en comparación con la diversidad de las especies mencionadas. Las plantas citadas por los estudiantes de la escuela de la zona urbana, la mitad fueron similares a los que se remite también a los estudiantes de la escuela rural. Se comprobó que el conocimiento que las nuevas generaciones tienen, relativo a las plantas medicinales es razonablemente representativo, y las familias son las transmisoras del mismo.

Palabras-clave: Etnobotánica. Conocimiento tradicional. Medio Ambiente.

\section{Introdução}

O uso de plantas entre as populações nordestinas indica um grande conhecimento dos recursos do ambiente e um sistema próprio de utilização desses recursos, constituindo uma vasta farmacopéia natural, boa parte proveniente dos recursos vegetais encontrados nos ambientes naturais ocupados por essas populações ou mantidos em ambientes de cultivo antrópico (MARTINS, 2012).

Maciel et al. (2002) colocam que o uso de plantas medicinais é uma prática baseada no conhecimento popular, sendo, muitas vezes, o único recurso terapêutico de muitas comunidades e grupos étnicos. As observações populares sobre o uso e a eficácia de plantas medicinais contribuem, de forma significativa, para a divulgação das ações terapêuticas dos vegetais prescritos, com frequência, pelos efeitos medicinais que produzem, tornando válidas as indicações terapêuticas que foram sendo adquiridas durante séculos. Giraldi e Hanazaki (2010) afirmam que a percepção de que as plantas têm ação curativa é uma das formas de relação entre populações humanas e plantas. Além disso, as práticas que se associam ao uso tradicional de plantas medicinais são, muitas vezes, as únicas opções disponíveis para várias comunidades, visando à manutenção da saúde ou o tratamento de doenças.

Sousa, Araújo e Santos (2007) observam que o interesse por plantas consideradas medicinais tem aumentado bastante, mostrando que alguns fatores estão induzindo a sua utilização, como a elevação do custo de vida em algumas regiões ou a falta total das mínimas condições humanas, seja para cura de doenças ou para alimentação, consistindo, atualmente, numa busca na melhoria da qualidade de vida e resgate do conhecimento popular.

Segundo Pilla, Amorozo e Furlan (2006), à medida que a relação com a terra se transforma pela modernização do campo e o contato com a sociedade nacional se intensifica, a rede de transmissão do conhecimento sobre plantas pode sofrer alterações, seja pelos meios de comunicação ou por agentes sociais. Resgatar o conhecimento e as técnicas terapêuticas 
dessas plantas é uma maneira de deixar registrado um modo de aprendizado informal que contribui para a valorização da medicina popular, além de gerar informações sobre a saúde da comunidade local. Olguin et al. (2007) ressaltam que o conhecimento tradicional, de interesse para a ciência, explica-se muito pela existência de relatos verbais da observação sistemática de fenômenos biológicos feitos por pessoas, algumas tão perspicazes quanto os cientistas.

Nesse raciocínio, torna-se importante verificar o conhecimento tradicional em diferentes esferas da sociedade, inclusive na escola, e em diferentes níveis. A escola de Ensino Fundamental representa um importante papel na formação do indivíduo, além de possuir potencialidade na criação de conceitos e na estimulação de uma atitude questionadora e crítica em relação à realidade e, assim sendo, a investigação do conhecimento da utilização dos efeitos terapêuticos, nessa etapa do ensino, torna-se de grande importância (SANTOS; DIAS; MARTINS, 1995).

Nesse contexto, o presente trabalho teve como objetivo verificar se há diferença entre o conhecimento acerca do uso medicinal de plantas apresentado por alunos de duas escolas de Ensino Fundamental da zona rural e urbana no município de Viçosa do Ceará, estado do Ceará, bem como visou proporcionar o aumento de informações sobre o conhecimento e uso das mesmas por esta parcela social.

\section{Material e Métodos}

O estudo foi realizado em duas escolas de Ensino Fundamental no município de Viçosa do Ceará, Ceará: Escola A, situada no distrito de Quatiguaba, zona urbana, e Escola B, situada no Sítio Tope, zona rural da referida cidade. Em ambas as escolas, os questionários foram aplicados nas suas respectivas turmas de $8^{\circ}$ ano, abrangendo 15 e 24 alunos, respectivamente, perfazendo um total de 39 alunos.

Seguindo a metodologia de Moraes et al. (2010), aplicou-se um questionário semiestruturado aos alunos das escolas, abordando questões a respeito do conhecimento e uso de plantas para fins terapêuticos e de sua importância. Aos alunos, foi solicitado que mantivessem o anonimato durante o preenchimento dos questionários, procedimento também adotado por Silva e Marisco (2013).

Para efeito comparativo, foi utilizada a média aritmética simples quanto ao número de plantas citadas por aluno de cada turma, bem como o teste de Mann-Whitney $(\mathrm{p}<0,05)$ para comparação entre as médias das citações.

Foi determinada a diversidade e similaridade das espécies citadas pelos grupos, utilizando para isso os índices de Shannon-Wienner e Sorensen (MAGURRAN, 1989), respectivamente. Para o cálculo da diversidade, foram feitas correções nos tamanhos amostrais pelo método da rarefação (GOTELLI; COLWELL, 2001) e, posteriormente, realizada a comparação das médias pelo teste de Kruskal-Wallis ( $\mathrm{p}<0,05)$.

Elaborou-se uma lista com as espécies citadas e seus atributos, conforme descrição dos participantes dos grupos analisados.

\section{Resultados e Discussão}

Observando os resultados, quando questionados sobre o que seria uma planta medicinal, verificou-se que, na escola da zona urbana, $73 \%$ afirmaram que é uma planta que serve para fazer remédio, $13 \%$ responderam que é uma planta que ajuda a melhorar a saúde das pessoas, enquanto $7 \%$ disseram que é uma planta que serve para o tratamento de algumas 
doenças e 7\% que é uma planta que cura qualquer tipo de doença. Já na escola de zona rural, $42 \%$ afirmaram que é uma planta que serve para fazer remédio, $42 \%$ colocaram que é uma planta que serve para o tratamento de algumas doenças, $4 \%$ responderam que ajuda a melhorar a saúde das pessoas, $4 \%$ que é uma planta que cura qualquer tipo de doença e $8 \%$ não responderam.

Percebe-se que a visão sobre o que é uma planta medicinal é um pouco restrita nos alunos entrevistados das duas escolas, dos quais algumas respostas apresentaram-se equivocadas, como a definição de que as plantas medicinais servem para tratar qualquer tipo de doença, indicando falta de informação sobre o assunto. Isso também foi observado por Brito (2013) o qual, ainda que tenha abordado alunos de ensino médio, verificou que os alunos apresentam um conhecimento pouco significativo a respeito do tema em questão.

Por sua vez, Cruz, Joaquim e Furlan (2011), em pesquisa realizada com alunos de ensino fundamental da rede particular de São José dos Campos-SP, atribuem como possível justificativa do desconhecimento dos alunos com relação à definição do que é uma planta medicinal o fato de que as residências dos mesmos se localiza nas áreas urbanas das cidades.

Já Viveiros, Goulart e Alvim (2004) apontaram, em seus resultados de estudo, que a maioria dos estudantes universitários entrevistados possuía um conhecimento satisfatório de plantas, embora, nesse caso, além de ser herdado através do saber popular, seja oriundo do conhecimento científico adquirido no âmbito do universo acadêmico.

Quando perguntados sobre quais plantas medicinais eles conheciam e para quais tratamentos elas seriam indicadas, além da parte da planta que era utilizada, foram citadas, ao todo, 21 plantas, sendo que o número médio de citações por aluno da escola da zona urbana foi de 1,6 , enquanto que o da escola de zona rural foi de 3,5.

O número de citações de plantas diferiu, significativamente, nos grupos das escolas urbana e rural $(Z=3,2765 ; p=0,001)$, sendo que estes últimos demonstraram um maior conhecimento de plantas medicinais e seu uso para fins terapêuticos. Apesar desse fato, os alunos da escola de zona urbana possuem um conhecimento razoável sobre as mesmas, tendo em vista que todos os alunos indicaram, pelo menos, uma planta e sua ação terapêutica. Quando comparada à diversidade de espécies citadas (Figura 1), colocados os dois grupos a mesmo nível amostral, não é verificada diferença acentuada (rural- $\mathrm{H}^{\prime}=2.49$; urbana-H'=2.19) uma vez que não diferem significativamente $(\mathrm{H}=1,13 ; \mathrm{p}=0,28)$.

Figura 1- Relação entre a diversidade observada de plantas citadas na escola urbana e os intervalos de segurança da amostra da escola rural rarefeita, seguindo o método de Gotelli e Colwell (2001). Convenção: $H^{\prime}=$ Diversidade (Shannon- Wienner); ICI = Intervalo de Confiança Superior; ICS = Intervalo de Confiança Inferior. 


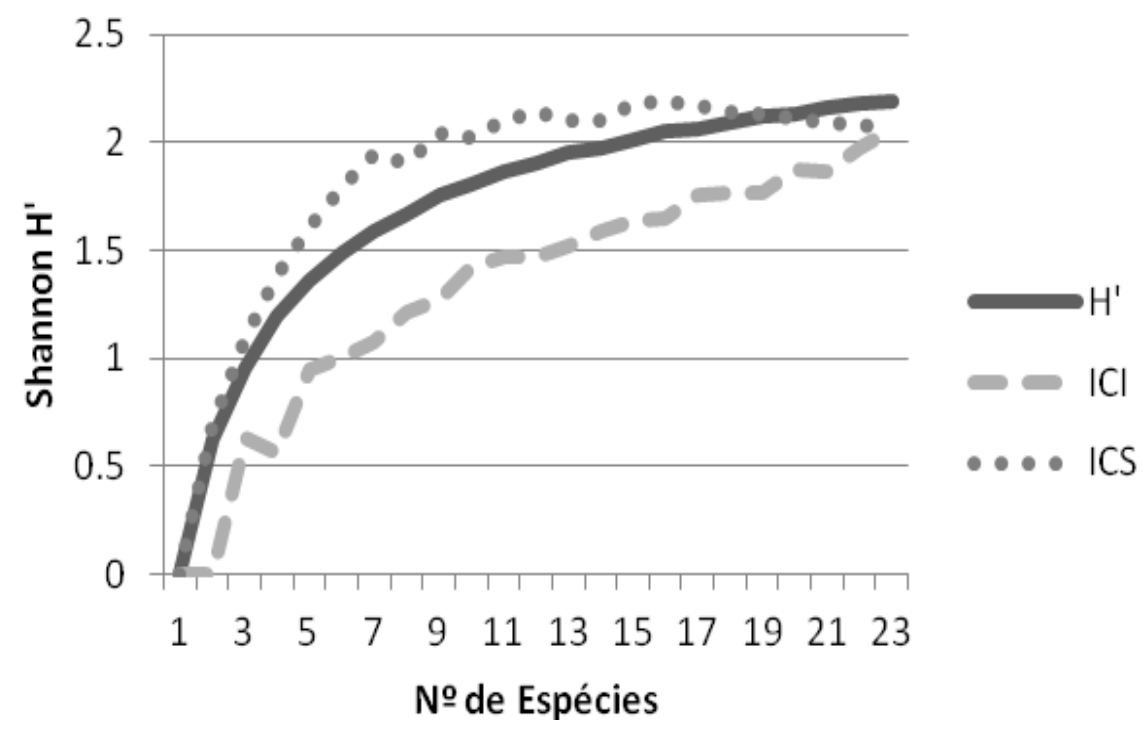

Fonte: Pesquisa direta (2014)

Vicente (2013), ao investigar o conhecimento popular sobre plantas medicinais conhecidas por uma comunidade escolar de ensino fundamental em Joinville-SC, observou que $32 \%$ dos alunos souberam citar mais de duas plantas medicinais conhecidas, 39\% disseram conhecer pelo menos um nome de uma planta e $29 \%$ não souberam citar nenhuma planta.

Carneiro, Rodrigues e Cantanhede Filho (2012) obtiveram resultados semelhantes em seu estudo, realizado com alunos de duas escolas de São Luís-MA, uma urbana e outra rural, com objetivo de realizar um levantamento sobre a utilização de plantas medicinais, onde afirmou que pessoas da zona rural possuem maior conhecimento sobre essas plantas, atribuindo a isso o fato de que há uma menor disponibilidade de serviços médicos e de acesso a medicamentos alopáticos.

Roque, Rocha e Loiola (2010) avaliam que as comunidades rurais estão intimamente ligadas aos usos medicinais das plantas devido a estas serem, na maioria das vezes, o único recurso disponível para o tratamento de doenças nessas regiões.

Sobre as plantas citadas pelos alunos da escola de zona urbana, metade foi similar $(\mathrm{Ss}=0.5)$ àquelas também referidas pelos alunos da escola rural (Arruda, Boldo, Capim-santo, Cidreira, Hortelã, Malva). Dentre algumas indicações mencionadas pelos alunos da escola urbana, $21,7 \%$ foram para a hortelã (Mentha $x$ villosa), 17,4\% para o capim-santo (Cymbopogon citratus), malva (Malva sylvestris) e boldo (Plectranthus barbatus). Já em relação a algumas plantas citadas pelos alunos entrevistados na escola de zona rural, 21,7\% indicaram a malva (Malva sylvestris), 15,7\% a cidreira (Lippia alba), 10,8\% o capim-santo (Cymbopogon citratus), 8,4\% a laranjeira (Citrus aurantium), 6,0\% a hortelã (Mentha $x$ villosa), $6 \%$ o eucalipto (Eucalyptus sp), enquanto a alfavaca (Ocimum gratissimum), arruda (Ruta graveolens) e aroeira (Myracrodruon urundeuva) tiveram 4,8\% de citações cada. Nessa última, foram citadas plantas medicinais nativas, como a aroeira, o que não se observa na escola de zona urbana, em que apenas plantas medicinais cultivadas foram colocadas como conhecidas pelos alunos pesquisados. 
Alguns estudos também encontraram a malva, a cidreira e a hortelã como as mais citadas entre os estudantes entrevistados (NASCIMENTO et al., 2012; LACERDA et al., 2013), sendo que o estudo de Lacerda et al. (2013) também obteve um número significativo de citações quanto ao capim-santo, só que em menor proporção, estando, dessa forma, em concordância com os resultados encontrados nesta pesquisa.

A Tabela 1 destaca, dentre outros aspectos, a porcentagem de citações de cada planta entre os alunos das duas escolas e a parte utilizada citada pelos alunos, com predominância absoluta do uso da folha.

TABELA 1 - Plantas medicinais citadas pelos alunos das duas escolas, Escola A, situada no distrito de Quatiguaba, zona urbana e Escola B, situada no Sítio Tope, no município de Viçosa - CE e suas indicações de uso.

\begin{tabular}{|c|c|c|c|c|c|c|c|}
\hline $\begin{array}{l}\text { Nome } \\
\text { Popular }\end{array}$ & $\begin{array}{c}\text { Família } \\
\text { Nome científico }\end{array}$ & \begin{tabular}{|c|} 
Uso popular \\
entre os \\
alunos da \\
escola de \\
zona \\
urbana \\
\end{tabular} & \begin{tabular}{|} 
Uso popular \\
entre os \\
alunos da \\
escola de zona \\
rural
\end{tabular} & $\begin{array}{l}\text { Uso trazido na } \\
\text { literatura* }\end{array}$ & \begin{tabular}{|} 
Parte \\
utilizada \\
citada \\
pelos \\
alunos
\end{tabular} & \begin{tabular}{|c|} 
Percentual de \\
citações entre \\
os alunos da \\
escola de \\
zona urbana
\end{tabular} & $\begin{array}{l}\text { Percentual } \\
\text { de citações } \\
\text { entre os } \\
\text { alunos da } \\
\text { escola de } \\
\text { zona rural } \\
\end{array}$ \\
\hline Abacateiro & $\begin{array}{c}\text { Lauraceae } \\
\text { Persea americana } \\
\text { Mill. }\end{array}$ & - & Inflamação & \begin{tabular}{|c|} 
Diurético, antirreumático, \\
carminativo, antianêmico, \\
antidiarreico, anti- \\
infeccioso para os rins e \\
bexiga, estomáquico, \\
emenagogo e balsâmico \\
\end{tabular} & Folha & - & $4 \%$ \\
\hline Alfavaca & $\begin{array}{c}\text { Lamiaceae } \\
\text { Ocimum } \\
\text { gratissimum L. }\end{array}$ & - & Dor de barriga & \begin{tabular}{|c|} 
Antitérmico, \\
antiespasmódico gástrico \\
estimulante digestivo, \\
combate problemas das \\
vias respiratórias, \\
infecções bacterianas e \\
parasitas intestinais \\
\end{tabular} & Folha & - & $17 \%$ \\
\hline Aroeira & $\begin{array}{l}\text { Anacardiaceae } \\
\text { Myracrodruon } \\
\text { urundeuva } \\
\text { (Engl.) Fr. All. }\end{array}$ & - & $\begin{array}{c}\text { Dor de cabeça, } \\
\text { inflamação }\end{array}$ & \begin{tabular}{|} 
Afecções cutâneas e \\
problemas do aparelho \\
urinário e das vias \\
respiratórias; anti- \\
inflamatório e cicatrizante
\end{tabular} & Casca & - & $17 \%$ \\
\hline Arruda & \begin{tabular}{|c} 
Rutaceae \\
Ruta graveolens L.
\end{tabular} & $\begin{array}{l}\text { Dor de } \\
\text { ouvido }\end{array}$ & Dor de ouvido & \begin{tabular}{|c|} 
Tratamento de desordens \\
menstruais, inflamações \\
na pele, dor de ouvido, \\
dor de dente, febre, \\
câimbras, doenças do \\
fígado, verminose
\end{tabular} & Folha & $7 \%$ & $17 \%$ \\
\hline Babosa & $\begin{array}{c}\text { Xanthorrhoeaceae } \\
\text { Aloe vera }(\mathrm{L} .) \\
\text { Burm. f }\end{array}$ & - & Queimaduras & \begin{tabular}{|c|} 
Cicatrizante nos casos de \\
queimaduras e ferimentos \\
superficiais da pele; nas \\
contusões, entorces e \\
dores reumáticas
\end{tabular} & Folha & - & $4 \%$ \\
\hline Beladona & $\begin{array}{c}\text { Solanaceae } \\
\text { Atropa } \\
\text { belladonnaL. }\end{array}$ & - & Dor de barriga & - & Folha & - & $4 \%$ \\
\hline
\end{tabular}




\begin{tabular}{|c|c|c|c|c|c|c|c|}
\hline $\begin{array}{c}\text { Nome } \\
\text { Popular }\end{array}$ & $\begin{array}{c}\text { Família } \\
\text { Nome científico }\end{array}$ & \begin{tabular}{|c|} 
Uso popular \\
entre os \\
alunos da \\
escola de \\
zona \\
urbana
\end{tabular} & \begin{tabular}{|} 
Uso popular \\
entre os \\
alunos da \\
escola de zona \\
rural
\end{tabular} & $\begin{array}{l}\text { Uso trazido na } \\
\text { literatura* }\end{array}$ & \begin{tabular}{|c|} 
Parte \\
utilizada \\
citada \\
pelos \\
alunos
\end{tabular} & \begin{tabular}{|c|} 
Percentual de \\
citações entre \\
os alunos da \\
escola de \\
zona urbana
\end{tabular} & $\begin{array}{c}\text { Percentual } \\
\text { de citações } \\
\text { entre os } \\
\text { alunos da } \\
\text { escola de } \\
\text { zona rural }\end{array}$ \\
\hline Beterraba & $\begin{array}{l}\text { Chenopodiaceae } \\
\text { Beta vulgaris } \mathrm{L} \text {. }\end{array}$ & Anemia & - & - & Folha & $7 \%$ & - \\
\hline Boldo & $\begin{array}{c}\text { Lamiaceae } \\
\text { Plectranthus } \\
\text { barbatus Andr. }\end{array}$ & $\begin{array}{l}\text { Dor de } \\
\text { barriga }\end{array}$ & Dor de barriga & \begin{tabular}{|c|} 
Carminativo, analgésico, \\
sedativo, estimulante do \\
apetite, tratamento da \\
insuficiência hepática e \\
inflamação da vesícula
\end{tabular} & Folha & $26 \%$ & $4 \%$ \\
\hline Camomila & $\begin{array}{l}\text { Asteraceae } \\
\text { Chamomilla } \\
\text { recutita (L.) } \\
\text { Rauschert }\end{array}$ & - & Calmante & $\begin{array}{l}\text { Sedativo, carminativo, } \\
\text { auxilia nas funções } \\
\text { digestivas, combate } \\
\text { cólicas e estimula o } \\
\text { apetite }\end{array}$ & Folha & - & $8 \%$ \\
\hline $\begin{array}{l}\text { Capim- } \\
\text { santo }\end{array}$ & $\begin{array}{c}\text { Poaceae } \\
\text { Cymbopogon } \\
\text { citratus Stapf }\end{array}$ & $\begin{array}{l}\text { Calmante, } \\
\text { gripe, } \\
\text { resfriado, } \\
\text { febre }\end{array}$ & $\begin{array}{c}\text { Calmante, dor } \\
\text { de cabeça }\end{array}$ & $\begin{array}{l}\text { Calmante, analgésico, } \\
\text { espasmoliítico }\end{array}$ & Folha & $26 \%$ & $38 \%$ \\
\hline Cidreira & $\begin{array}{c}\text { Verbenaceae } \\
\text { Lippia alba (Mill.) } \\
\text { Brow. }\end{array}$ & $\begin{array}{l}\text { Dor de } \\
\text { barriga }\end{array}$ & \begin{tabular}{|c|} 
Azia, dor de \\
barriga, dor de \\
estômago, \\
vômitos
\end{tabular} & \begin{tabular}{|c|} 
Calmante, dispepsia, \\
estados gripais, bronquite \\
crônica, enxaqueca, \\
problemas \\
gastrointestinais, dores de \\
origem reumática \\
\end{tabular} & Folha & $7 \%$ & $54 \%$ \\
\hline Courama & $\begin{array}{l}\text { Crassulaceae } \\
\text { Bryophyllum } \\
\text { pinata (Lam.) } \\
\text { Oken }\end{array}$ & - & $\begin{array}{l}\text { Dor de } \\
\text { estômago }\end{array}$ & $\begin{array}{c}\text { Furúnculos, tosse, } \\
\text { anexite, gastrite; } \\
\text { atividades antialérgicas, } \\
\text { antiúlceras e } \\
\text { imunossupressivas }\end{array}$ & Folha & - & $13 \%$ \\
\hline Couve & \begin{tabular}{|} 
Brassicaceae \\
Brassica oleracea \\
L.
\end{tabular} & Gastrite & - & - & Folha & $7 \%$ & - \\
\hline Eucalipto & $\begin{array}{c}\text { Myrtaceae } \\
\text { Eucalyptus sp. }\end{array}$ & - & $\begin{array}{l}\text { Febre, gripe, } \\
\text { resfriado }\end{array}$ & \begin{tabular}{|c|} 
Anticatarral, tratamento \\
da gripe, congestão nasal \\
e sinusite
\end{tabular} & Folha & - & $21 \%$ \\
\hline Gengibre & $\begin{array}{l}\text { Zingiberaceae } \\
\text { Zingiber } \\
\text { officinalis } \\
\text { Roscoe }\end{array}$ & $\begin{array}{c}\text { Dor de } \\
\text { garganta }\end{array}$ & - & $\begin{array}{l}\text { Tratamento da asma, } \\
\text { bronquite, dispepsia, } \\
\text { cólicas e menorragia, } \\
\text { ação estimulante } \\
\text { digestiva, carminativo, } \\
\text { antivomitativo, anti- } \\
\text { inflamatório, } \\
\text { antirreumático }\end{array}$ & Raiz & $7 \%$ & - \\
\hline
\end{tabular}




\begin{tabular}{|c|c|c|c|c|c|c|c|}
\hline $\begin{array}{c}\text { Nome } \\
\text { Popular }\end{array}$ & $\begin{array}{c}\text { Família } \\
\text { Nome científico }\end{array}$ & \begin{tabular}{|} 
Uso popular \\
entre os \\
alunos da \\
escola de \\
zona \\
urbana
\end{tabular} & \begin{tabular}{|} 
Uso popular \\
entre os \\
alunos da \\
escola de zona \\
rural
\end{tabular} & $\begin{array}{c}\text { Uso trazido na } \\
\text { literatura* }\end{array}$ & \begin{tabular}{|c|} 
Parte \\
utilizada \\
citada \\
pelos \\
alunos
\end{tabular} & \begin{tabular}{|c|} 
Percentual de \\
citações entre \\
os alunos da \\
escola de \\
zona urbana
\end{tabular} & $\begin{array}{c}\text { Percentual } \\
\text { de citações } \\
\text { entre os } \\
\text { alunos da } \\
\text { escola de } \\
\text { zona rural }\end{array}$ \\
\hline Goiabeira & $\begin{array}{c}\text { Myrtaceae } \\
\text { Psidium guajava } \\
\text { L. }\end{array}$ & - & $\begin{array}{l}\text { Diarreia, dor } \\
\text { de barriga }\end{array}$ & $\begin{array}{c}\text { Antidiarreico, tratamento } \\
\text { de inflamações da boca e } \\
\text { da garganta }\end{array}$ & Folha & - & $13 \%$ \\
\hline Hortelã & $\begin{array}{c}\text { Lamiaceae } \\
\text { Mentha x villosa } \\
\text { Huds. }\end{array}$ & $\begin{array}{l}\text { Gripe, } \\
\text { resfriado, } \\
\text { dor de } \\
\text { barriga }\end{array}$ & Gripe & \begin{tabular}{|c|} 
Antigripal, \\
descongestionante nasal, \\
antiviral, antidispéptico, \\
antivomitativo, antiúlcera, \\
anti-inflamatório, \\
tratamento da má digestão \\
\end{tabular} & Folha & $33 \%$ & $21 \%$ \\
\hline Laranjeira & \begin{tabular}{|c|} 
Rutaceae \\
Citrus aurantium \\
L.
\end{tabular} & - & \begin{tabular}{|} 
Dor de barriga, \\
dor de \\
estômago, \\
pressão alta
\end{tabular} & $\begin{array}{c}\text { Ação digestiva, } \\
\begin{array}{c}\text { expectorante, diurética e } \\
\text { hipotensora }\end{array}\end{array}$ & $\begin{array}{c}\text { Casca do } \\
\text { fruto }\end{array}$ & - & $29 \%$ \\
\hline Malva & \begin{tabular}{|c|} 
Malvaceae \\
Malva sylvestris L.
\end{tabular} & \begin{tabular}{|} 
Gripe, dor de \\
garganta, \\
tosse, \\
resfriado, \\
diarreia
\end{tabular} & $\begin{array}{c}\text { Dor de barriga, } \\
\text { dor de cabeça, } \\
\text { gripe }\end{array}$ & $\begin{array}{c}\text { Bronquite crônica, tosse, } \\
\text { asma, enfisema pulmonar, } \\
\text { coqueluche, colite, } \\
\text { constipação intestinal }\end{array}$ & Folha & $26 \%$ & $75 \%$ \\
\hline Mastruz & $\begin{array}{l}\text { Chenopodiaceae } \\
\text { Chenopodium } \\
\text { ambrosioides L. }\end{array}$ & Inflamação & Inflamação & $\begin{array}{l}\text { Antirreumático, anti- } \\
\text { helmíntico, tratamento da } \\
\text { gripe, bronquite e } \\
\text { tuberculose }\end{array}$ & Folha & $7 \%$ & $4 \%$ \\
\hline $\begin{array}{c}\text { Quebra- } \\
\text { pedra }\end{array}$ & $\begin{array}{c}\text { Euphorbiaceae } \\
\text { Phyllanthus } \\
\text { urinaria L. }\end{array}$ & - & Pedra nos rins & $\begin{array}{c}\text { Tratamento da litíase } \\
\text { renal, reumatismo gotoso, } \\
\text { antiviral na hepatite B }\end{array}$ & Raiz & - & $4 \%$ \\
\hline
\end{tabular}

Fonte: os autores

*De acordo com Lorenzi e Matos (2002)

Guerra et al. (2010) relacionam a citação ao uso da folha ao fato de que as folhas possuem maior disponibilidade, durante a maior parte do ano, se comparadas a outras partes da planta, além de possuírem quantidades maiores de princípios ativos que proporcionam a cura de enfermidades. O uso da folha não prejudica a planta, pois a sua obtenção não implica, necessariamente, em matá-la. Dessa forma, sabendo da necessidade de extração paulatina e contínua, o usuário possui, em geral, interesse em preservá-la, contribuindo, assim, com a preservação daquela respectiva espécie. A partir disso, o usuário passará, também, a ter uma relação de melhor conhecimento daquela, pois, para que o uso de uma planta medicinal seja eficaz é preciso conhecê-la, entender como atua no organismo e como deve ser preparada e armazenada, aproveitando melhor o princípio ativo da mesma (SANTOS; ROSITO, 2012).

Ao serem questionados, na escola de zona urbana, se usam as plantas como remédio, todos os 15 alunos abordados afirmaram ter utilizado, em algum momento, essas plantas por diferentes motivos, sendo que destes, $67 \%$ por não fazer mal à saúde, $26 \%$ por preferência em relação a remédios industrializados e $7 \%$ indicaram que é um método eficaz. Da mesma 
forma, todos os 24 alunos questionados na escola de zona rural também disseram que utilizam plantas medicinais como remédio, sendo $54 \%$ das citações porque não faz mal à saúde, $42 \%$ por preferência em relação a remédios industrializados e $4 \%$ por serem acostumados a utilizar plantas medicinais.

Bourscheid (2011), em sua pesquisa com alunos de ensino médio, ao destacar a escola como espaço ideal para trabalhar a discussão e o conhecimento sobre a importância do cultivo de plantas medicinais, também observou que $100 \%$ dos alunos utilizam as plantas como remédio, enquanto Lacerda et al. (2013), objetivando investigar o conhecimento sobre plantas medicinais em três segmentos da sociedade do município de Pombal-PB, observaram que $71 \%$ dos discentes de ensino médio de uma escola pública de zona urbana afirmaram utilizálas, contribuindo com os resultados desta pesquisa.

Quando indagados se já viram resultado no tratamento com plantas medicinais, na escola da zona urbana, 33\% dos alunos entrevistados disseram que sim, enquanto $47 \%$ falaram às vezes e $20 \%$ que nunca viram resultado. Na escola da zona rural, $25 \%$ afirmaram que sempre viram resultado e $75 \%$ indicaram que às vezes. Silva (2012), buscando identificar o nível de conhecimento sobre plantas medicinais em uma comunidade escolar de ensino fundamental no meio rural do município de Cachoeira do Sul-RS, constatou que $99 \%$ dos entrevistados afirmaram conhecer resultados no uso de plantas medicinais, convergindo com os resultados deste estudo.

Ao serem perguntados através de quem (ou como) aprenderam a utilizar plantas medicinais, na escola da zona urbana, $46 \%$ dos alunos afirmaram ter aprendido com os avós, $20 \%$ com os pais, $20 \%$ aprenderam através da televisão, $7 \%$ com profissionais de saúde e $7 \%$ com vizinhos. Já na escola de zona rural, $75 \%$ dos alunos disseram que aprenderam com os pais e $25 \%$ com os avós, ficando o aprendizado, nesse caso, restrito à família, resultado também observado no estudo realizado por Moraes et al. (2010), em um levantamento etnobotânico de plantas medicinais com alunos de ensino médio, constatando que pais e avós foram os transmissores principais do conhecimento sobre o uso de plantas para fins terapêuticos. Messias et al. (2015) afirmam que as pessoas conhecedoras do maior número de espécie de plantas são aquelas que aprenderam com a tradição familiar, livros e/ou combinação de ambos ou, ainda, através de outras pessoas.

Nesse contexto, Schardong e Cervi (2000) mencionam que o conhecimento que se tem da planta, relativo às suas propriedades medicinais, é uma questão cultural que foi passada de geração em geração, o que traz o resgate do conhecimento popular sobre as plantas medicinais e permite a conservação dessas espécies dentro de um universo familiar.

Da mesma forma, Leite et al. (2014), buscando analisar o conhecimento e a utilização de plantas medicinais entre alunos de ensino fundamental de uma escola pública, observaram que quase a totalidade da comunidade estudada possui o conhecimento transmitido através dos familiares, passando de pai para filho. Isto também foi evidenciado por Paulino et al. (2011) ao avaliarem o conhecimento de estudantes universitários sobre o uso das mesmas.

Igualmente, Santos (2000), afirmou que a oralidade, no âmbito da família, é via privilegiada na transmissão desses saberes, sugerindo que esta prática representa um elo da apropriação histórica ocorrida no transcurso da construção de uma nova tradição, confirmando os resultados desta pesquisa.

Ao responderem sobre onde conseguem a planta para fazer remédio, na escola da zona urbana, $33 \%$ dos alunos disseram que adquirem na vegetação próxima às suas casas, $27 \%$ no próprio quintal, $27 \%$ no quintal de vizinhos ou parentes e $13 \%$ comprando no mercado ou feira livre. Na escola sita à zona rural, $54 \%$ assinalaram que adquirem no próprio quintal, $29 \%$ 
no quintal de vizinhos ou parentes, $4 \%$ comprando no mercado ou feira livre e $13 \%$ na vegetação próxima às casas. Esse último percentual encontra-se baixo, provavelmente, tendo em vista que uma boa parte dessas citações foi dirigida para a opção - no próprio quintal pois, na zona rural do município onde está situada a escola, nas áreas ao redor das casas a vegetação nativa se funde a esses locais chamados de terreiros, não havendo uma delimitação física de espaço como em um quintal de uma casa na cidade. Nossos resultados convergem com os de Mauli, Fortes e Antunes (2007) ao analisarem os alunos de zona urbana de Cascavel-PR, no qual a maioria das respostas indicam que aqueles obtêm as plantas no próprio quintal e no mercado, assim como os de Passos (2013) o qual também observou a predominância da opção - própria casa - em seu estudo, o qual objetivou diagnosticar o conhecimento e uso tradicional de plantas medicinais com alunos de ensino fundamental. Duarte, Goetz e Boff (2013) afirmam que os jovens que possuem horta própria em suas casas constituem a fase mais representativa no que diz respeito à construção do convívio social e no compartilhamento do saber, entre os parentes mais próximos, sobre plantas medicinais.

Favilla e Hoppe (2011) defendem que as plantas medicinais, usadas dentro de uma comunidade, resultam em uma forma de aplicar, efetivamente, vertentes de educação ambiental, pois, além de ocorrer a preservação da espécie utilizada, torna o ser humano mais próximo à natureza e contribui para conservar o conhecimento popular.

Por fim, quando questionados se consideram importante a utilização de plantas medicinais, todos os alunos, de ambas as escolas, afirmaram positivamente. Na escola de zona urbana, $47 \%$ ressaltaram a importância porque são mais eficientes que os remédios alopáticos vendidos em farmácias, $20 \%$ porque melhoram a saúde e causam bem-estar, $13 \%$ porque servem para o tratamento de algumas doenças e $7 \%$ porque não possuem condições financeiras de comprar remédios alopáticos. Já na escola de zona rural, 33\% dos alunos relataram que é importante porque são mais eficientes que os remédios alopáticos vendidos em farmácias, $24 \%$ que ajudam a melhorar a saúde das pessoas, $17 \%$ porque servem para o tratamento de algumas doenças, $13 \%$ porque não há a necessidade de se deslocar até a farmácia em busca de remédio. Outros motivos, para ambas as escolas, também foram relatados: porque é mais barato (5\%); porque sabem como utilizá-las (4\%); porque confiam mais nas plantas do que em remédios comprados em farmácias (4\%).

Em seu estudo com alunos de ensino médio, Brito (2013) observou que a importância das plantas medicinais demonstrada pelos alunos está atrelada à cura de doenças e na produção de medicamentos a partir dessas plantas. Em sua pesquisa em uma comunidade escolar de ensino fundamental, David et al. (2014) destacaram que o uso de plantas como remédio, além de ser muito importante para pessoas de zona rural, devido à distância do atendimento médico, também o é para as pessoas da zona urbana, atrelando isso à dificuldade no atendimento médico e ao custo de medicamentos alopáticos industrializados.

Ao fazer uso das plantas medicinais, as pessoas apresentam conhecimentos e estratégias de curas que surgem ao longo das gerações. Isto enfatiza a importância de se estudar a origem do conhecimento, buscando entender de onde veio e há quanto tempo vem sendo conservada na comunidade, o que pode contribuir para a valorização do conhecimento popular (SCHARDONG; CERVI, 2000).

\section{Considerações Finais}

Pôde-se verificar, com alunos do ensino fundamental dos grupos pesquisados, que o conhecimento que as novas gerações possuem a respeito de plantas medicinais é relativamente representativo, sendo a família, na figura dos pais e avós, os principais transmissores do conhecimento, o que demonstrou que esse hábito ainda é difundido. Os 
alunos da zona rural apresentaram maior conhecimento quanto ao uso medicinal das plantas, embora, considerando a diversidade de plantas citadas em mesmo nível amostral, essa diferença não se apresenta significativa. A diferença pode estar associada a um maior contato que os habitantes da zona rural possuem com a vegetação próxima às suas casas e ao fato de que muitos dispõem apenas dessa forma de tratamento dos seus males.

O conhecimento acerca da medicina caseira, muitas vezes, é transmitido transgeracionalmente, sendo essas práticas ainda comuns dentro dos grupos analisados, fazendo com que seja necessário o desenvolvimento de novos estudos como forma de investigar a ideia que as novas gerações possuem a respeito do tema, além de buscar a preservação do conhecimento sobre a ação medicinal das plantas e de sua importância. Nesse ponto de vista, este estudo tornou-se relevante pois os resultados encontrados evidenciam que os conhecimentos a respeito do uso de plantas medicinais estão sendo transmitidos aos jovens dentro da amostra estudada, contribuindo para o aumento de informações sobre o tema em questão. Além disso, indicou um conhecimento dos recursos vegetais do ambiente e um sistema próprio de utilização desses recursos.

\section{Referências}

BOURSCHEID, M.L.L. Plantas medicinais: um legado da escola para a família. 2011. 16f. Monografia (Especialização em Educação do Campo) - Curso de Especialização em Educação do Campo, Universidade Federal do Paraná, Matinhos, 2011.

BRITO, A.A. Diagnóstico do uso e importância das plantas medicinais entre docentes e discentes do ensino médio do município de Brejo do Cruz-PB. 2013. 51f. Monografia (Graduação em Ciências Biológicas) - Curso de Licenciatura em Ciências Biológicas a Distância da Universidade Federal da Paraíba, São Bento, 2013.

CARNEIRO, F.J.C.; RODRIGUES, K.A.F.; CANTANHEDE FILHO, A.J. Estudo de plantas medicinais usadas pela comunidade do IFMA e do bairro do Quebra Pote. Acta Tecnológica, São Luís/MA, v.7, n.1, p.13-19, 2012.

CRUZ, L.P.;; JOAQUIM, W.M. FURLAN, M.R. O estudo de plantas medicinais no ensino fundamental: uma possibilidade para o ensino da botânica. Thesis, São Paulo, ano VII, n.15, p.78-92, jan.-jun. 2011.

DAVID, M.; MAMEDE, J.S.S.; DIAS, G.S. et al. Uso de plantas medicinais em comunidade escolar de Várzea Grande, Mato Grosso, Brasil. Biodiversidade, Rondonópolis, v.13, n.1, p.38-50. 2014.

DUARTE, A.M.; GOETZ, E.R.; BOFF, P. Etnoconhecimento de plantas medicinais em área urbana: para além da terapêutica. Cadernos de Agroecologia, Porto Alegre/RS, v.8, n.2, p.1-5, Nov. 2013.

FAVILLA, M.A.C.; HOPPE, J.M. As plantas medicinais como instrumento de educação ambiental. Monografias ambientais, v.3, n.3, p.468-475. 2011.

GIRALDI, M.; HANAZAKI, N. Uso e conhecimento tradicional de plantas medicinais no Sertão do Ribeirão, Florianópolis, SC, Brasil. Acta Botanica Brasilica, São Paulo, v.24, n.2, p.395-406, Apr/Jun. 2010.

GOTELLI, N; COLWELL, R. K. Quantifying biodiversity: procedures and pitfalls in the measurement and comparison of species richness. Ecology Letters, v. 4, n.4, p. 379-391, Jul. 2001. 
GUERRA, A. M.N.M.; PESSOA, M.F.; SOUZA, C.S.M. et al. Utilização de plantas medicinais pela comunidade rural Moacir Lucena, Apodi-RN. Bioscience Journal, Uberlândia, v.26, n.3, p. 442-450, May/Jun. 2010.

LACERDA, J.R.C.; SOUSA, J.S.; SOUSA, L.C.F.S. et al. Conhecimento popular sobre plantas medicinais e sua aplicabilidade em três segmentos da sociedade no município de Pombal-PB. Agropecuária Científica no Semiárido, Goiânia, v.9, n.1, p.14-23, jan-mar. 2013.

LEITE, I.A.; SOUSA, L.P.; MORAIS, A.M. et al. Plantas medicinais: conhecimento e utilização entre adolescentes da rede pública de ensino de Patos-PB. In: CONGRESSO NORDESTINO DE BIÓLOGOS, 4, 2014, João Pessoa. Anais eletrônicos... João Pessoa: Rede Brasileira de Informações Biológicas - $\quad$ Rebibio, 2014. p.45-47. Disponível em: <http://congresso.rebibio.net/congrebio2014/anais2014.html>. Acesso em: 24 jul. 2016.

LORENZI, H.; MATOS, F.J.A. Plantas Medicinais no Brasil - Nativas e Exóticas. São Paulo: Instituto Plantarum, 2002. $512 \mathrm{p}$.

MACIEL, M.A.M.; PINTO, A.C.; VEIGA-JUNIOR, V.F.; GRYNBERG, N.F. et al. Plantas medicinais: a necessidade de estudos multidisciplinares. Química Nova, São Paulo, v.25, n.3, p.429438, May. 2002.

MAGURRAN, A. E. Ecological diversity and its measurement. New Jersey: Princeton University Press, 1989.

MARTINS, R.C. Plantas medicinais da Caatinga: uso e conhecimento popular em área urbana do município de Juazeiro-BA. 2012. 61f. Monografia (Curso de Especialização em Educação contextualizada para convivência com o Semiárido brasileiro) - Universidade do Estado da Bahia, Juazeiro, 2012.

MAULI, M.M.; FORTES, A.M.T.; ANTUNES, F. Cidadania e educação ambiental: plantas medicinais no contexto escolar. Acta Scientiae, Rio Grande do Norte, v.9, n.2, p.91-107, Mar. 2007.

MESSIAS, M.C.T.B.; MENEGATTO, M.F.; PRADO, A.C.C.; SANTOS B.R.; GUIMARÃES, M.F.M. Uso popular de plantas medicinais e perfil socioeconômico dos usuários: um estudo em área urbana em Ouro Preto, MG, Brasil. Revista Brasileira de Plantas Medicinais, Campinas, v.17, n.1, p.76-104, Jan./Mar. 2015.

MORAES, J.Q.; NUNES, J.R.S.; PESSOA, S.P.M. et al. Etnobotânica de plantas medicinais com alunos do Ensino Médio de um colégio estadual de Tangará da Serra-MT. In: CONGRESSO DE INICIAÇÃO CIENTÍfICA, 3., (JC), 2010, Cáceres/MT. Anais... Cáceres/MT: Pró-Reitoria de Pesquisa e Pós-Graduação - PRPPG, 2010. v. 6, 2010. Cód. 1549. ISSN ONLINE2237-9258. CDROM 2178-7492.

NASCIMENTO, C.S.; CLARO, H.R.; LIMA, J.P. et al. O uso de plantas medicinais na percepção dos estudantes, da Escola Estadual Marisa Mariano, de Barra do Garças-MT. Revista Eletrônica da Univar, v.2, n.8, p.1-5. 2012.

OLGUIN, C.F.A.; CUNHA, M.B.; BOSCO, C.B.D. et al. Plantas medicinais: estudo etnobotânico dos distritos de Toledo e produção de material didático para o ensino de ciências. Acta Scientiarum. Human and Social Sciences, Maringá, v.29, n.2, p.205-209. 2007.

PASSOS, D.P. Conhecimento tradicional e uso de plantas medicinais como fonte de recurso terapêutico por alunos do Colégio Carlos Pereira da Silva de Cabaceiras da Silva-BA. 2013. 36f. 
Monografia (Graduação em Ciências da Natureza) - Curso de Licenciatura em Ciências da Natureza, Universidade Federal do Recôncavo da Bahia, Cruz das Almas, 2013.

PAULINO, R.C.; HENRIQUES, G.P.S.A.; COELHO, M.F.B. et al. Conhecimento sobre plantas medicinais entre alunos da Universidade Federal do Semi Árido, Mossoró, RN. Revista Verde, Maringá, v.6, n.4, p.78-90, out-nov. 2011.

PILLA, M.A.C.; AMOROZO, M.C.M.; FURLAN, A. Obtenção e uso de plantas medicinais no distrito de Martim Francisco, Município de Mogi Mirim, SP, Brasil. Acta Botanica Brasilica, São Paulo, v.20, n.4, p.789-802, Mar. 2006.

ROQUE, A.A.; ROCHA, R.M.; LOIOLA, M.I.B. Uso e diversidade de plantas medicinais da Caatinga na comunidade rural de Laginhas, município de Caicó, Rio Grande do Norte (Nordeste do Brasil). Revista Brasileira de Plantas Medicinais, Botucatu, v.12, n.1, p.31-42, Jan/Mar. 2010.

SANTOS, F.S.D. Tradições populares de uso de plantas medicinais na Amazônia. História, Ciências, Saúde - Manguinhos [online], Rio de Janeiro, v.6, supl., p.919-939, Set. 2000.

SANTOS, M.G.; DIAS, A.G.P.; MARTINS, M.M. Conhecimento e uso da medicina alternativa entre alunos e professores de primeiro grau. Revista de Saúde Pública, São Paulo, v.29, n.3, p.221-227, Jun. 1995.

SANTOS, B.M.M.; ROSITO, J.M. Uso de plantas medicinais como instrumento de conscientização: responsabilidade social e ambiental. Revista Eletrônica do Mestrado em Educação Ambiental, Rio Grande/RS, v.7, n.7, p.1478-1491. 2012.

SCHARDONG, R.M.F.; CERVI, A.C. Estudos etnobotânicos das plantas de uso medicinal e místico na comunidade de São Benedito, Bairro São Francisco, Campo Grande- MS. Acta Biologica Paranaense, Curitiba, v.29, n.2, p.187-217. 2000.

SILVA, M.R. A utilização do conhecimento de plantas medicinais como ferramenta para estimular a preservação ambiental. Monografias Ambientais, Santa Maria, v.6, n.6, p.1354-1380, Mar. 2012.

SILVA, T.S.S.S.; MARISCO, G. Conhecimento etnobotânico dos alunos de uma escola pública no munícipio de Vitória da Conquista/BA sobre plantas medicinais. Revista de Biologia e Farmácia, Paraíba, v.9, n.3, p.1-12. 2013.

SOUSA, C.G.; ARAÚJO, B.R.N.; SANTOS, A.T.P. Inventário Etnobotânico de Plantas Medicinais na Comunidade de Machadinho, Camaçari-BA. Revista Brasileira de Biociências, Porto Alegre, v.5, supl.1, p.549-551, Jul. 2007.

VICENTE, L.A.A. Conhecimento e uso popular das plantas medicinais utilizadas por famílias de uma comunidade escolar do bairro Glória em Joinville (SC). 2013. 75f. Monografia (Graduação em Ciências Biológicas) - Curso de Licenciatura em Ciências Biológicas, Universidade Federal de Santa Catarina, Florianópolis, 2013.

VIVEIROS, A.A.; GOULART, P.F.; ALVIM, N.A.T. A influência dos meios sociocultural e científico no uso de plantas medicinais por estudantes universitários da área da saúde. Escola Anna Nery Revista de Enfermagem, Rio de Janeiro, v.8, n.1, p.62-70, Abril. 2004.

Versão recebida em: 21/10/2015

Aceite em: 10/12/2015 